Research Article

\title{
Beneficiation of Commiphora africana Plant: Extraction and Application of Green Softener on Cotton Fabric
}

\author{
Fisaha Asmelash $(\mathbb{D})$ and Million Ayele $(\mathbb{D}$ \\ Ethiopian Institute of Textile and Fashion Technology, Bahir Dar University, Bahir Dar, Ethiopia \\ Correspondence should be addressed to Million Ayele; milliti2000@gmail.com
}

Received 3 April 2021; Revised 5 August 2021; Accepted 16 December 2021; Published 27 December 2021

Academic Editor: Guangwu Fang

Copyright (c) 2021 Fisaha Asmelash and Million Ayele. This is an open access article distributed under the Creative Commons Attribution License, which permits unrestricted use, distribution, and reproduction in any medium, provided the original work is properly cited.

\begin{abstract}
This paper aims at the extraction and application of eco- and user-friendly natural gum obtained from Commiphora Africana tree. The result obtained is also compared with fabric treated with a commercial softener of the same concentration. The gum was extracted by puncturing the stem of the plant and the extracted gum was applied directly to $100 \%$ cotton fabric through a padding process with different concentrations of extracted gum (i.e., 20 gram per litre (g/l), $25 \mathrm{~g} / \mathrm{l}$, and $30 \mathrm{~g} / \mathrm{l}$ ). Another similar fabric sample was treated with a silicon softener of the same concentration. The fabric samples treated with both natural gum and silicon softener were tested for their stiffness, crease recovery, and drapability. The results show that the change in fabric softness depends on the concentration of softener used in both cases. As the concentration of the softener increased, there was a decrease in bending length and drape coefficient for both fabric samples. The drape coefficient of fabric sample treated with natural gum has a comparable result with fabric treated with silicon/commercial softener. Maximum increases in recovery angle were seen in fabric treated with natural gum at a concentration of $30 \mathrm{~g} / \mathrm{l}$.
\end{abstract}

\section{Introduction}

Cotton is the main textile fiber that has a distinctive blend of properties, with great strength, long-lasting, smoothness, excellent dyeability, and biodegradability, and it has been used for apparel for several years [1]. The softness of the fabric is an essential comfort property of cotton fabric which is mostly used to describe how the fabric hangs around an object or how it senses upon touching. Softening is one of the most important chemical finishing processes in wearable textiles [2]. Application of softener to textile material can give smoother surface, pleasant handle, good drapability, excellent flexibility, and pliability. Due to such functional reasons, softening agents are used in the finishing of textile fabrics. Softening agents are also applied by the users during the laundering of fabric at their homes [3].

The softening agent should be freely miscible or dispersible in the water and readily absorbed by the fabric. Consequently, to increase fabric handle, many types of softening agents are used commercially which are mainly categorized into four groups: nonionic softeners (polyethylene emulsion, silicone emulsion, polyoxyethylene derivatives, etc.), anionic softeners (sulphated oils, sulphated alcohols, soaps, oil emulsions, etc.), reactive softeners (methylolstearmide, octadecyl ethylene urea, etc.), and cationic softeners (quaternary ammonium and other cationic products) [4]. Nowadays, organic softener obtained from plant sources is attracting the interest of researchers as well as finished fabric users.

Commiphora africana is a small tree or bush shrub that mainly originates in the woodland of savannah and drier parts of tropical Africa. "The bark is grey or greenish on the bole, reddish on the branches, and peeling off in thin papery strips." The name Commiphora africana is derived from a Greek word meaning "gum bearing." It yields oil and gums resins used for different applications.

Commiphora africana is primarily known for its gum resin products, some of which are galbanum, bdellium, and African myrrh that are sources of feedstock for making fibers, polyester resins, films, vanishes, and plasters. A 
chemical characteristic of the plant was studied to evaluate the pharmacological effects of the gums on isolated rabbit ileum $[5,6]$. The main chemical compounds in Commiphora africana oil are sesquiterpenes and sesquiterpene-lactones which have antitumor properties [7]. However, the polymer obtained can be used as a softening agent in the finishing of cotton fabric. Owing to its organic nature and being natural polymers, natural gum extracted from Commiphora Africana are eco- and user-friendly than synthetic softeners.

The main objective of this work is extraction of natural gum from Commiphora africana plant to produce organic, eco-friendly, and user-friendly natural softening agents (gum) which is not tried by any researcher before for textile application. The gum was extracted by puncturing the stem of the plant and the extracted gum was applied directly to $100 \%$ cotton fabric through the padding process. The fabric treated with both natural and silicon softener was tested for stiffness, crease recovery, and drapability.

\section{Materials and Methods}

\subsection{Materials}

2.1.1. Commiphora africana. Commiphora africana plant was obtained from the Tigray region, Ethiopia.

2.1.2. Fabric. Hundred percent half-bleached cotton fabric samples were obtained from Bahir Dar Textile Share Company. The characteristics of the fabric were measured in the Ethiopian Institute of textile and fashion technology laboratory (warp and weft density, yarn count with, thickness, and GSM (gram per square meter)). The characteristic of the fabric is mentioned in Table 1.

2.1.3. Chemicals. Commercial grade silicone softener and acetic acid were obtained from Ethiopian Institute of Textile and Fashion Technology laboratory, Bahir Dar University, Bahir Dar, Ethiopia.

\subsection{Methods}

2.2.1. Extraction of Softener. Commiphora africana plant's gum (adhesive) which has a characteristic of softener was extracted by piercing the stem of the Commiphora africana plant with an axe, and then, the oozing sap was collected with a beaker, as shown in Figure 1. The sap was then brought to the laboratory and kept at room temperature.

2.2.2. Application Methods. Both silicon and natural softeners were applied to the cotton fabric by the pad dry cure method with the help of padding mangle under the same conditions. Three different concentrations of natural gum and silicon softener with equal concentration were prepared $(20,25$, and $30 \mathrm{~g} / \mathrm{l}$ for natural softener and 20,25 , and $30 \mathrm{~g} / \mathrm{l}$ for silicon softener as well). One litre of water was boiled for $10 \mathrm{~min}$ and 20 grams, 25 grams, and 30 grams of both natural and silicon softeners were added to the hot water and stirred until a homogeneous solution was attained. Six $40 \mathrm{~cm} x$
TABle 1: Cotton fabric sample specifications.

\begin{tabular}{lc}
\hline Property & Fabric specification \\
\hline GSM & $140 \mathrm{~g} / \mathrm{m}^{2}$ \\
Thickness & $0.394 \mathrm{~mm}$ \\
Yarn count (weft and warp) & $22 \mathrm{Ne}$ \\
Warp density & $29 \mathrm{ends} / \mathrm{cm}$ \\
Weft density & 17 picks $/ \mathrm{cm}$ \\
\hline
\end{tabular}



FIGURE 1: The extraction method of softener from Commiphora africana.

$40 \mathrm{~cm}$ fabric samples were prepared and padded with the solution of each softener and left for $30 \mathrm{~min}$ at $50^{\circ} \mathrm{C}$. Then, the samples were passed through the padding mangle and dried and cured simultaneously at $150^{\circ} \mathrm{C}$ for $5 \mathrm{~min}$ in the drying machine. One $40 \mathrm{~cm} \times 40 \mathrm{~cm}$ controlled fabric sample was also prepared for comparison purposes. One gram per litre of acetic acid was added to the natural gum of each concentration for fixation purposes.

2.2.3. Properties of the Treated Fabrics. The treated fabric samples with both natural gum and commercial softener were tested for stiffness and drapability to examine the effectiveness of the natural gum and to compare it with silicon/ commercial softener. The following tests were carried out:

(1) Fabric Stiffness. Stiffness test was carried out according to ISO: 6490-1971 standards using Shirley stiffness tester machine (ISO: 6490 and 1971). [8]

(2) Fabric Drapability. Drape coefficient test was tested according to ISO: 8357-1977 Standards using CUSICK drape tester machine (ISO: 8357 and 1977) [9]

(3) Fabric Crease Recovery. Crease recovery test was carried out according to ISO: 4681-1968 Standards with Shirley crease recovery tester machine (ISO: 4681 and 1968) [10]

\section{Results and Discussion}

For most wearable apparel, cotton fabrics are treated with softening agents for pleasant hand and improved drape ability [11]. In the current study, fabric samples treated with silicon and natural softeners showed a dissimilar result based on the concentration of applied softener. The higher the concentration, the better the softness of the fabric. The treated fabrics were evaluated for stiffness, drapability, and crease recovery.

3.1. Effect of Softener on Fabric Stiffness. Applying a softening agent on dyed, printed, and bleached cotton fabric or laundry rinsing can result in soft touch to the cloth. This 
property can influence the aesthetic appearance as well as the comfort of the fabric. Previous study showed that the lower the bending length (the lower the stiffness), the better the fabric softness [12]. The bending length is a measure of the interaction between fabric weight and fabric stiffness in which a fabric bends under its weight. It reflects the stiffness of fabric when bent in one plane under the force of gravity and is one component of the drape.

Figure 2 shows that untreated fabric exhibited a bending length of $3.7 \mathrm{~cm}$ in the warp direction and $3 \mathrm{~cm}$ in the weft direction; however, at a concentration of $20 \mathrm{~g} / \mathrm{l}$, the bending length was reduced to $2.48 \mathrm{~cm}$ in the warp and $2.32 \mathrm{~cm}$ in the weft direction for silicon softener. Similarly, it reduced to $2.51 \mathrm{~cm}$ in the warp and $2.47 \mathrm{~cm}$ in the weft direction for the natural gum. The decrement in bending length for both silicon softener and natural gum was noticed as the concentration increased. The minimum bending length is observed at $30 \mathrm{~g} / \mathrm{l}$, for both silicone softener and natural gum (i.e., the bending length of fabric treated with silicon softener was $1.28 \mathrm{~cm}$ in the warp and $1.22 \mathrm{~cm}$ in the weft direction and that of fabric treated with natural softener was $1.32 \mathrm{~cm}$ in the warp and $1.28 \mathrm{~cm}$ in the weft direction). This is in agreement with previous studies that a decrease in bending length is due to the additive and adhesive nature of softener which decreases the friction between the fibers in the fabric [4]. Softener lowers the fiber-to-fiber friction. It is believed that this process causes a reduction in friction between fibers, leaving cotton clothes softened. Thus, the softness of clothes after using a softener depends on the friction between fibers [13]. The natural gum exhibited a result nearly similar to silicon softener with a small deviation revealing gum extracted from the Cammiphora africana plant can be an alternative softener that can replace silicon softener.

3.2. Effect of Softener on Fabric Drapability. The drape is the term used to describe the way a fabric hangs under its weight. Fabric drapability is an important factor from the aesthetic point of view. Good draping leads to the fitting of fabric over a surface without undesirable wrinkling or tearing. According to Hunter and Fan, there is a significant correlation between stiffness and drape coefficient [11]. The drape coefficient (F) has been developed to describe the degree of drape and drape shape (configuration and modality). A lower $F$ value means the fabric is softer, and its drapability is better, and in other words, the higher the drape coefficient $(\mathrm{F})$, the stiffer the fabric.

The effect of softener on fabric drapability is shown in Figure 3. The drape coefficient of the controlled sample was $78.57 \%$, and at $20 \mathrm{~g} / \mathrm{l}$ concentration of silicon and natural gum, the drape coefficient reduced to $77.74 \%$ and $77.54 \%$, respectively. Increasing the concentrations of both softeners reduced the drape coefficient, and at $30 \mathrm{~g} / \mathrm{l}$ concentration of both silicon and natural softener, the drape coefficient reduced to $73.18 \%$ for silicon softener and $73.26 \%$ for the natural gum. The reason for the decreasing of drape coefficient upon increasing of softener/gum concentration is that the softening agent decreases fiber-to-fiber friction leaving

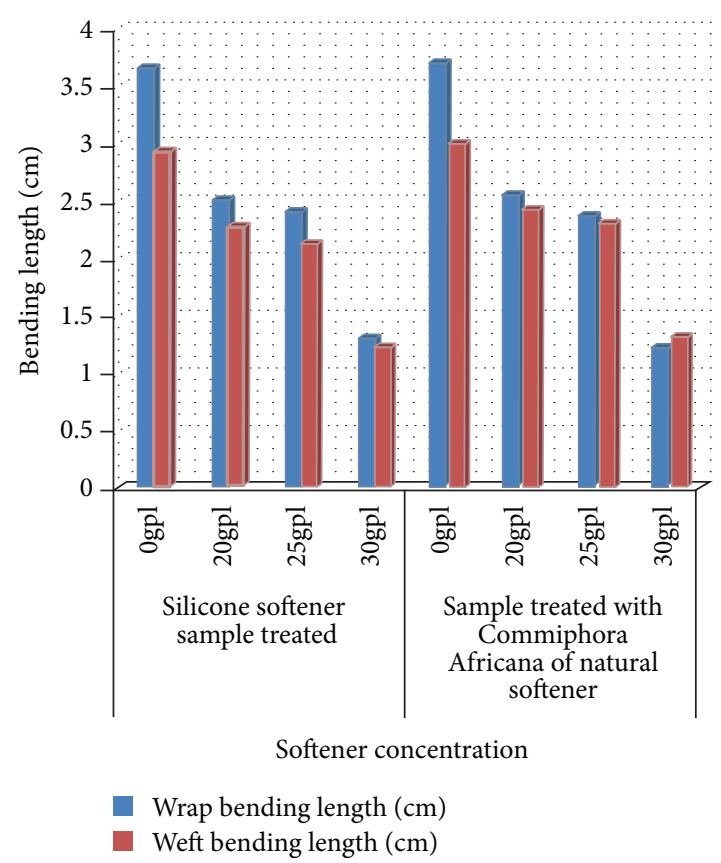

Figure 2: Effect of softener on fabric stiffness.

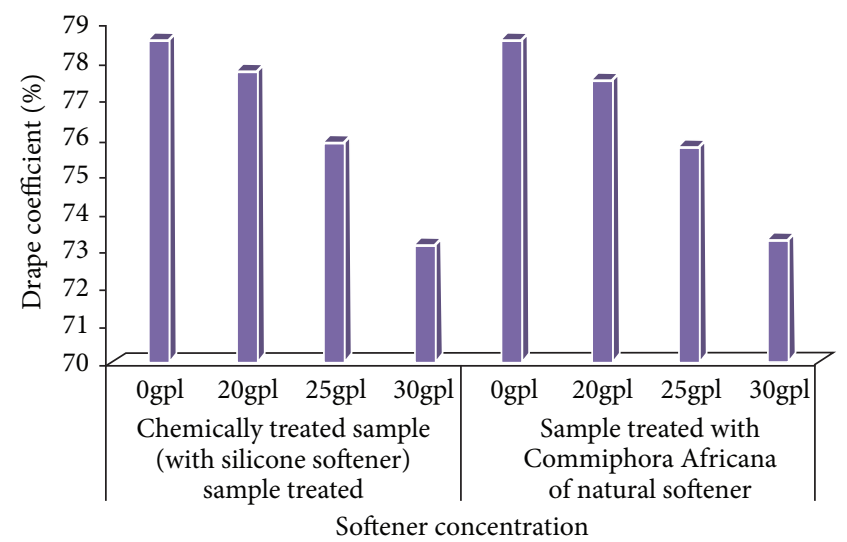

Figure 3: Effect of softener on fabric drapability.

the fabric softer; the softer fabric is then easily draped under its weight. On increasing the concentration of both silicon and natural softener, the drape coefficient decreased which signifies the application of softener on fabric sample has an effect on its drapability. As it is revealed in Figure 3, a natural gum extracted from Commiphora africana plant had a comparable result with silicon softener on the drapability of the fabric. The lower the drape coefficient, the softer the fabric.

3.3. Effect of Softener on Crease Recovery. The magnitude of the crease recovery angle is an indication of the ability of a fabric to recover from accidental creasing. Since the chain slippage under moist conditions is responsible for wrinkling, it is logical that cross-linking of adjacent cellulose chains should be a way of improving crease recovery. Softening agents are acting as cross-linking agents (cross-linking of 


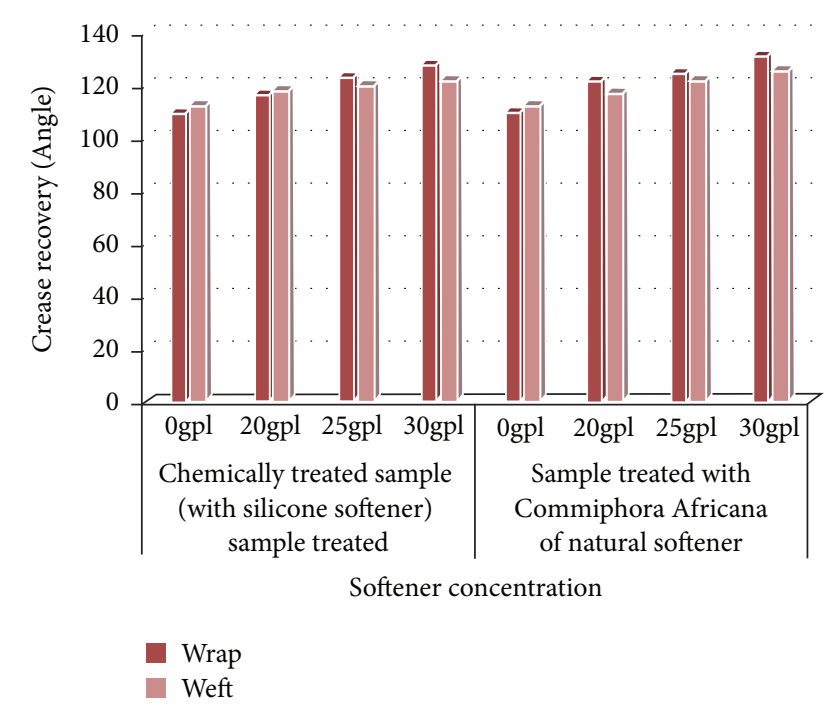

Figure 4: Effect of softener on crease recovery.

adjacent cellulose chains) and improve crease recovery of the fabric. The higher the crease recovery, the softer the fabric $[4,14]$. The effect of both silicon and extracted natural gum on crease recovery of the cotton fabric is depicted in Figure 4 . The crease recovery angle of the untreated sample was $109.2^{\circ}$ in the warp direction and $112.2^{\circ}$ in the weft direction. The crease recovery angle increases considerably upon the application of silicon softener and natural gum in both samples. On increasing the concentration of both silicon and natural gum, there was an increased recovery angle of the fabric. As the concentration of silicon softener increases from $20 \mathrm{~g} / \mathrm{l}$ to $30 \mathrm{~g} / \mathrm{l}$, the crease recovery angle of the fabric increased from $116.4^{\circ}$ to $127.7^{\circ}$ in the warp direction and from $117.2^{\circ}$ to $121.2^{\circ}$ in the weft direction. Similarly, as the concentration of natural gum increases from $20 \mathrm{~g} / \mathrm{l}$ to $30 \mathrm{~g} / \mathrm{l}$, the crease recovery angle of the fabric increased from $121.8^{\circ}$ to $131.2^{\circ}$ in the warp and from $117^{\circ}$ to $125.6^{\circ}$ in the weft direction, as shown in Figure 4. The result obtained with natural gum is comparable with the results of silicon softener. An increase of crease recovery angle in natural gum indicates that the treated fabric with natural gum is softer than untreated fabric which is in agreement with the previous study [15].

\section{Conclusion}

In conclusion, findings from the present study are in accordance with the previous study that supports the extraction and utilization of bio-based softeners from available biomass. The results obtained show that increasing the concentration of silicon softener and natural gum decreased the drape coefficient and bending length of the fabric. In the case of samples treated with natural gum, the drape coefficient decreased from $78.57 \%$ to $73.18 \%$, and bending length decreased from $7.3 \mathrm{~cm}$ to $1.28 \mathrm{~cm}$ and from $3 \mathrm{~cm}$ to $1.22 \mathrm{~cm}$ in the warp and weft direction, respectively. Similarly increasing increase recovery angle from $121.8^{\circ}$ to $131.2^{\circ}$ in the warp and from $117^{\circ}$ to $125.6^{\circ}$ in the weft direction results in improvement of fabric softness. In general, for half-bleached cotton fabric, comparable results (with silicon softener) were obtained by suitable treatment of the fabrics with natural gum made from Commiphora africana plant. There is a need to find the potential source of green softeners to replace the synthetic softeners available in today's market, which encourages the synthesis of green chemicals that reduce pollution load to the environment. The future study will entail the detailed characterization and optimization of the natural gum extraction process from the Commiphora africana plant for the same application and further textile applications such as multifunctional finish.

\section{Data Availability}

The fundamental data supporting the results of this research are reported in the manuscript.

\section{Conflicts of Interest}

The authors declare that they have no conflicts of interest.

\section{References}

[1] J. P. McCarthy and R. E. Drozdowski, "Household fabric softeners-the chemistry and characteristics of cationic softeners," Soap, Cosmetics, Chemical Specialties, vol. 65, no. 1, p. 33, 1989.

[2] D. Robati, "Synthesis of silicone softener and its characteristics on cotton fabric," Pakistan Journal of Biological Sciences, vol. 10, no. 4, pp. 676-678, 2007.

[3] S. J. Moon and T. J. Kang, "Effects of epoxide and silicone polymers on the mechanical and performance properties of wool fabric," Textile Research Journal, vol. 70, no. 12, pp. 1063-1069, 2000.

[4] F. Talebpour and I. Holme, "Effects of silicone-based softener on the easy-care finished cotton fabric," Indian Journal of Fibre \& Textile Research, vol. 31, pp. 444-449, 2006.

[5] M. K. Choudhury, E. C. Johnson, and A. S. Agbaji, "Chemical investigation of the bark of Commiphora africana burseraceae," Indian Journal of Pharmaceutical Sciences, vol. 62, pp. 311-312, 2000.

[6] J. Ekarika, C. Manash, O. A. Eseyin, and A. S. Udobre, "Pharmacological studies of the bark of commiphora africana (burseraceae)," Journal of Pharmacology and Toxicology, vol. 7, pp. 52-57, 2012.

[7] S. A. Gadir and I. M. Ahmed, "Commiphora myrrha and commiphora Africana essential oils," Journal of Chemical and Pharmaceutical Research, vol. 6, no. 7, pp. 151-156, 2014.

[8] ISO 6490:1971, Standard Test Method for Stiffness, ISO, Geneva, Switzerland, 1971.

[9] ISO 8357:1977, CUSICK Standard Test Method for Drape Test, ISO, Geneva, Switzerland, 1977.

[10] ISO 4681:1968, Shirley Standard Test Method for Crease Recovery Test, ISO, Geneva, Switzerland, 1968.

[11] L. Hunter and J. Fan, "Measuring and predicting fabric and garment drape," Advances in Apparel Production, Woodhead Publisher Series in Textile, Sawston, UK, pp. 7-25, 2008.

[12] S. Pant and N. Sonee, "A comparative study on the effect of finishing agents on stiffness and drape of Khadi fabric," Journal of Engineering Research and Application, vol. 4, no. 3, pp. 47-52, 2014. 
[13] T. Igarashi, N. Morita, Y. Okamoto, and K. Nakamura, "Elucidation of softening mechanism in rinse cycle fabric softeners. Part 1: effect of hydrogen bonding," Journal of Surfactants and Detergents, vol. 19, no. 1, pp. 183-192, 2016.

[14] R. N. Narkhedkar and R. K. Kupelur, "Effect of chemical treatments to improve crease recovery on cotton fabric," Fibre2Fashion.com, 2016.

[15] T. Hussain, S. Ali, and F. Qaiser, "Predicting the crease recovery performance and tear strength of cotton fabric treated with modified $\mathrm{N}$-methylol dihydroxyethylene urea and polyethylene softener," Coloration Technology, vol. 126, no. 5, pp. 256-260, 2010. 